\title{
Pulled elbow can easily be diagnosed and reduced by pediatricians - A clinic-based study on 49 cases
}

\author{
Biswajit Biswas', Mousumi Das², Atanu Roy³, Mithun Konar ${ }^{4}$, Monojit Mondal', \\ Archan $\mathrm{Sil}^{6}$ \\ ${ }^{1,3,4}$ Associate Professor, ${ }^{5}$ Senior Resident, ${ }^{6}$ Assistant Professor, Department of Pediatric Medicine, Burdwan Medical \\ College, Burdwan, West Bengal, India, ${ }^{2}$ Clinical Tutor, Department of Physiotherapy, Burdwan Institute of Medical and \\ Life Sciences, Burdwan, West Bengal, India
}

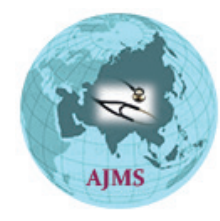

A B S T R A C T

Background: Pulled elbow is a common injury of early childhood that results in subluxation of the annular ligament due to a sudden longitudinal traction applied to the hand. Treatment is usually closed reduction with either a supination-flexion or a hyperpronation technique. Aims and Objectives: Present study is aimed to make pediatricians aware of the fact that most of such cases can be easily diagnosed and successfully reduced in office settings without much fear and complications. Materials and Methods: All cases with typical history and clinical presentation were included in the study and were subjected to supination-flexion maneuver. When the first attempt failed, a second attempt using the same technique was performed. After failure of the second attempt, hyperpronation was tried. Results: Among 49 patients included in the study, $27(55.10 \%)$ were girls and $22(44.89 \%)$ were boys. Mean age at presentation was 20.12 months. All of them were below 4 years of age. Forty-five patients were successfully reduced on the first attempt using supination-flexion maneuver, 2 patients required a second attempt using same technique. One patient was reduced with hyperpronation technique 15 minutes after first 2 attempts failed. Only 1 patient required referral to an orthopedic expert as all 3 attempts were in vain, but the child eventually recovered. Conclusion: All pediatricians should learn to diagnose and treat the condition to reduce delay in treatment and avoid complications.

Key words: Pulled elbow; Pediatrics; Supination-flexion maneuver; Hyperpronation

\section{Access this article online}

Website:

http://nepjol.info/index.php/AJMS DOI: 10.3126/ajms.v11i3.27769

E-ISSN: 2091-0576

P-ISSN: 2467-9100

Copyright (c) 2020 Asian Journal of Medical Sciences

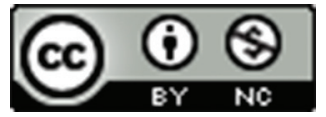

This work is licensed under a Creative Commons Attribution-NonCommercial 4.0 International License.

\section{INTRODUCTION}

Pulled elbow (nursemaid's elbow) is a common injury in childhood. ${ }^{1}$ It is caused by axial traction on the extended arm while the forearm is pronated such as when a child is pulled at the wrist to prevent a fall or picked up from the floor by their hand or the child tossing and turning with his or her arm under the body. ${ }^{2}$ The underlying mechanism involves slippage of the annular ligament off of the head of the radius followed by the ligament getting stuck between the radius and humerus. ${ }^{3,4}$ Children between the ages of 1 and 4 are most susceptible to this type of injury, and it is slightly more common in girls and in the left arm., ${ }^{5,6}$ The child with a pulled elbow commonly experiences sudden acute pain in elbow, forearm, wrist or shoulder ${ }^{7}$ and refuses to use the affected arm holding it close to his or her body. ${ }^{6}$ No obvious swelling or injury can be seen around affected elbow joint. On presentation, it may not be unusual for the child to be calm and sometimes even to be able to play. ${ }^{8}$

Most of these cases are brought first to the nearby paediatrician by the frightened parents. However, it is commonly unrecognised or misdiagnosed and unnecessary investigations are often prescribed. Even if diagnosed, most of them are usually referred to orthopedician due to lack of knowledge or experience further delaying the treatment and adding more suffering to the child and the family. 


\section{MATERIAL AND METHODS}

Present prospective observational study was carried out in a busy pediatric clinic which runs two shifts a day (morning and evening) and six days in a week during the period from January, 2014 to December, 2019. All patients with typical history and clinical presentation were included. Those with significant local swelling around elbow joint, bruising and ecchymosis, polytrauma, marked deformity were excluded.

After initial assessment, all children were subjected to supination and flexion maneuver (Figure 1) without use of any analgesic agent. Child was made to sit on mother's lap and distracted. Elbow was grabbed with one hand putting fingers over radial head. Other hand was used to hold the wrist joint. Supination of the forearm followed by flexion was performed in quick succession. A click could be felt or heard by the person performing the reduction as the radial head re-enters into the annular ligament.

In case the first attempt failed, the same technique was repeated once. When both the attempts did not yield any success, the child was rested for 15 minutes, a dose of paracetamol was given and the other common method hyperpronation (Figure 2) was tired. In this technique, the patient stays on the mother's lap facing the examiner; grabbing the elbow with one hand, the examiner's opposite hand firmly grabs the distal forearm and applies the hyperpronation.

Successful reduction is confirmed by a satisfying "click" at the time of reduction and/or the child starting to use full movement of the affected elbow joint, including pronation and supination, in 10 to 15 minutes after the reduction.

All data were collected and analysed by simple descriptive statistics using SPSS 26.0 software (IBM Corporation, USA).

\section{RESULTS}

A total of 49 patients were included in the study. Among them, $27(55.10 \%)$ were girls and 22 (44.89\%) were boys (Table 1).

The mean age was 20.12 months, ranging from 7 to 39 months. Out of all 49, nine (18.4\%) were 1year or below, $37(75.5 \%)$ were between 1 to 3 years and $3(6.1 \%)$ were above 3 years of age. None of the patients in our study group was below 6 months or above 4 years of age.

Majority $(51 \%, \mathrm{n}=25)$ of our patients had left arm involvement. $23(46.9 \%)$ children had involvement of the right arm. One female child aged 13 months had both the arms affected.

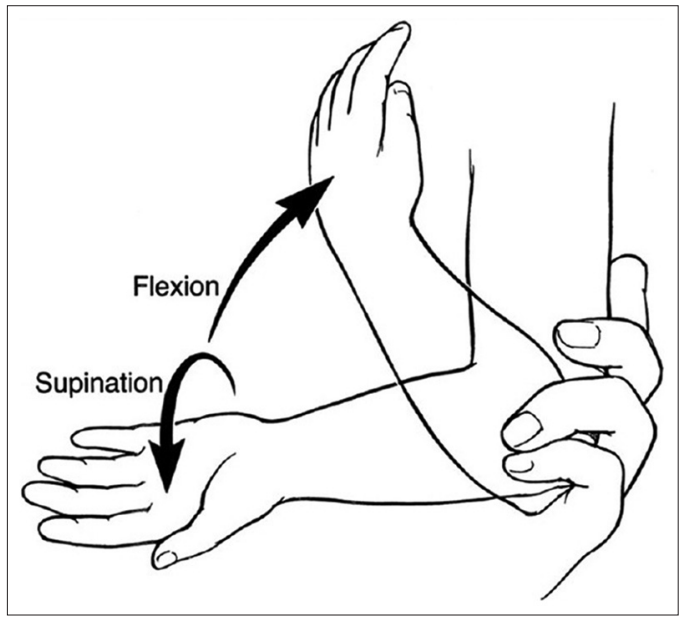

Figure 1: Supination-flexion technique

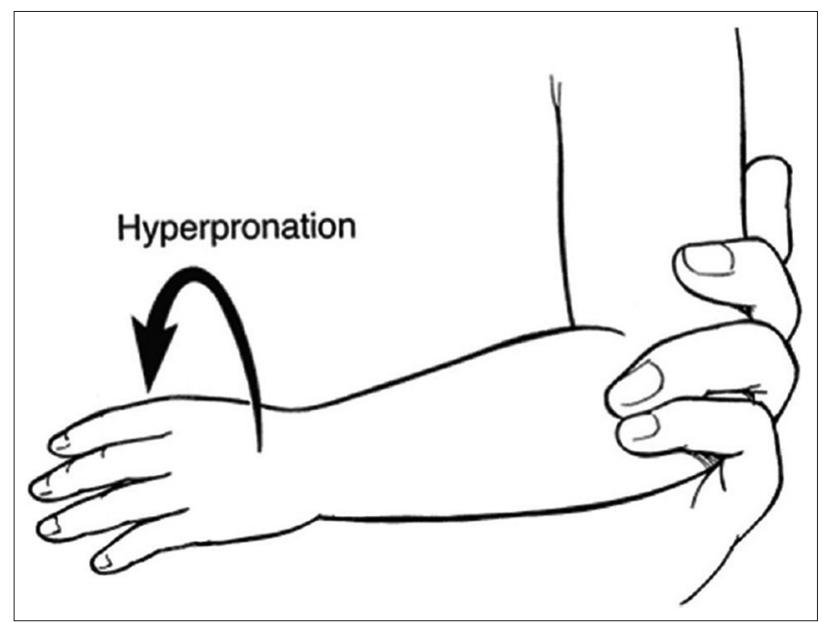

Figure 2: Hyperpronation technique

Time delay between onset of the event and arrival to the clinic was as follows: 31 patients $(63.3 \%)$ arrived within 6 hours, $9(18.4 \%)$ in between 6 and 12 hours, $8(16.3 \%)$ in between 12 to 24 hours and $1(2 \%)$ beyond 24 hours. Mean arrival time was 6.88 hours.

Majority ( $n=21,42.9 \%$ ) of the children in the study group could not locate the site of pain. 19 children (38.8\%) complained of pain in elbow and 9 (18.4) pointed pain both in forearm and elbow.

In 31 children (63.3\%), caregivers did not understand how the event took place. In 17 children (34.7\%), it happened while child was being tried to pull up. In 1 case, baby was found tossing in bed with arms under their body before the problem was noticed.

Supination-flexion technique was administered to all children diagnosed with the condition after initial physical assessment. In 45 patients $(91.8 \%$ ) reduction was successful on the first attempt (Figure 3). In 2 patients 


\begin{tabular}{|c|c|c|}
\hline Attribute & Description & Percentage (\%) \\
\hline Gender & $\begin{array}{l}\text { Male: } 27 \\
\text { Female: } 22\end{array}$ & $\begin{array}{l}55.10 \\
44.89\end{array}$ \\
\hline Age group & $\begin{array}{l}\text { Less than } 6 \text { months: } 0 \\
7 \text { months to } 12 \\
\text { months: } 9 \\
13 \text { months to } 36 \\
\text { months: } 37 \\
\text { More than } 36 \text { months: } 3\end{array}$ & $\begin{array}{c}00 \\
18.40 \\
75.50 \\
6.10\end{array}$ \\
\hline Hand affected & $\begin{array}{l}\text { Left: } 25 \\
\text { Right: } 23 \\
\text { Both: } 1\end{array}$ & $\begin{array}{c}51 \\
46.90 \\
2.00\end{array}$ \\
\hline $\begin{array}{l}\text { Time delay } \\
\text { between onset } \\
\text { of event and } \\
\text { arrival to the } \\
\text { clinic }\end{array}$ & $\begin{array}{l}\text { Less than } 6 \text { hours: } 31 \\
7 \text { to } 12 \text { hours: } 9 \\
13 \text { to } 24 \text { hours: } 8 \\
\text { More than } 24 \text { hours: } 1\end{array}$ & $\begin{array}{c}63.30 \\
18.40 \\
16.30 \\
2.00\end{array}$ \\
\hline $\begin{array}{l}\text { Mechanism of } \\
\text { injury }\end{array}$ & $\begin{array}{l}\text { Mechanism unclear: } 31 \\
\text { Pull on forearm: } 17 \\
\text { Roll over: } 1\end{array}$ & $\begin{array}{c}63.30 \\
34.70 \\
2.00\end{array}$ \\
\hline Site of pain & $\begin{array}{l}\text { Could not localize: } 21 \\
\text { Wrist: } 0 \\
\text { Forearm only: } 0 \\
\text { Forearm and elbow: } 9 \\
\text { Elbow only: } 19 \\
\text { Shoulder: } 0\end{array}$ & $\begin{array}{c}42.90 \\
00 \\
00 \\
18.40 \\
38.80 \\
00\end{array}$ \\
\hline $\begin{array}{l}\text { Number of } \\
\text { attempts needed } \\
\text { to achieve } \\
\text { reduction }\end{array}$ & $\begin{array}{l}1 \text { attempt with } \\
\text { supination-flexion: } 45 \\
2 \text { attempts using } \\
\text { supination-flexion: } 2 \\
3^{\text {rd }} \text { attempt using } \\
\text { hyperpronation: } 1 \\
\text { All } 3 \text { attempts failed: } 1\end{array}$ & $\begin{array}{l}91.80 \\
4.10 \\
2.00 \\
2.00\end{array}$ \\
\hline
\end{tabular}

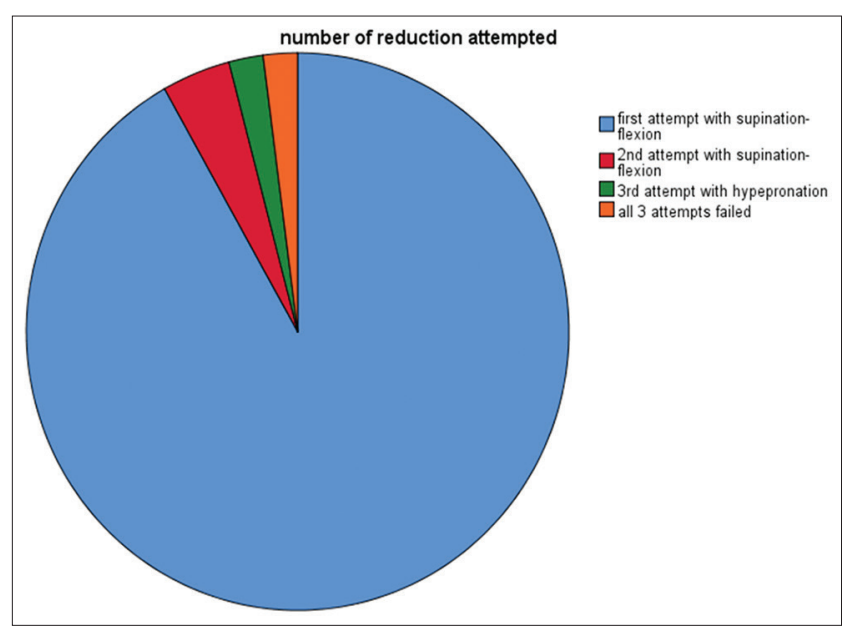

Figure 3: Pie chart showing numbers of attempt required to achieve successful reduction

(4.1\%) the same technique had to be repeated once to achieve reduction. In $2(4.1 \%)$ patients reduction was not achieved even after 2 attempts of supination-flexion maneuver. They were then tried the alternate method: hyperpronation after an interval of 15 minutes. It was possible to achieve reduction in one of these 2 patients.
Only in 1(2\%) patient in our study, all 3 attempts failed. Plain X-ray of the forearm and elbow was performed and the radiography showed no abnormality, but the patient refused to move his elbow. The child was referred to a nearby orthopaedic expert and the patient was immobilized in a long-arm cast for 1 week. The child subsequently recovered totally without any further recurrence in 1 year follow up.

\section{DISCUSSION}

Pulled elbow is a common upper extremity injury in younger children, whereby a pulling force onto an extended elbow joint and pronated forearm results in radial head subluxation. ${ }^{1-4}$

In most of the studies, girls have been found more affected than boys. ${ }^{5}$ In our study, $27(55.10 \%)$ were girls and $22(44.89 \%)$ were boys.

Mean age of the children affected was 20.12 months ranging from 7 months to 39 months. We had no case beyond 4 years of age. Previous studies of pulled elbow concluded that the injury typically occurs between the ages of 1 and 4 years with a peak incidence between 2 and 3 years. ${ }^{9-11}$ In children of younger age, the radius has a shape similar to a pole without a head or neck, thus being prone to easy dislocations. Conversely, in children over 7 years of age, the radial head expands via epiphyseal growth above the radial neck, therefore dislocation becomes much more difficult.

Takashi Irie, et al in their study ${ }^{6}$ found a peak frequency of injury at 6 months and around 2 years while comparing the two age groups: under-1-year-old and the 1-year-old or above. The analysis of injuries resulting from rolling over during sleep revealed a higher incidence for the under-1year-old group. Rolling over during sleep begins at about 5 months of age. The injury may occur when the child rolls over without coordination, thereby trapping the limb underneath the body. For the 1-year-old or older group, walking and running begins from about 1 year of age with frequent falls. Thus, pulled elbow may result from falling, or because of a pulling force applied to the arm by a parent or guardian.

Whatever be the mechanism of injury, pulled elbow is basically caused by a forceful traction applied on the pronated forearm. In $31(63.3 \%)$ patients in our study, caregivers were clueless about how the episode happened. In $17(34.7 \%)$ patients, history of a pulling force was evident. One $(2 \%)$ patient had a roll over injury. 
Among 49 children, 25 (51\%) had left arm and 23 (46.9\%) had right arm involvement. One child aged 13 months had both the elbow subluxated. In a study on 2331 pulled elbow cases over a period of 10 years, ${ }^{6}$ the left arm was found more commonly affected than the right and that the frequency of injuries to the left arm tends to increase with age. Explanation could be in most cases parents or guardians hold the child's left hand with their dominant right hand, and also that faster development of muscle strength in the child's dominant right arm may have a preventive effect on this arm with age.

All together $63.3 \%$ cases $(n=31)$ arrived within 0 to 6 hrs after the incident, whereas $18.4 \%$ of cases $(n=9)$ arrived within 6 to $12 \mathrm{hrs}, 16.3 \%(\mathrm{n}=8)$ arrived within 12 to 24 $\mathrm{hrs}$, and $2 \%$ of patients $(\mathrm{n}=1)$ after $24 \mathrm{hrs}$ in the office with painful and dangling arm. In Illingworth series, ${ }^{10}$ they have reported that $62 \%$ of cases attended office within $6 \mathrm{hrs}$. This time gap obviously is dependent on availability of health care services.

In our study most of the children ( $\mathrm{n}=21,42.9 \%$ ) could not localise pain to any particular area. However, $38.8 \%$ of patients $(n=19)$ complained of pain around elbow alone and $18.4 \%$ children $(n=9)$ pointed pain both in forearm and elbow. In Illingworth series, ${ }^{10} 53 \%$ of patients out of 64 complained of pain around elbow and 15 (23\%) were predominantly complaining of pain in the wrist. In contrast to this study, Serafin Garcia-Mata, et al found in their study of 115 patients, ${ }^{13} 30.4 \%$ of patients had pain in the wrist. So, the site of pain may be inconsistent and it can occur anywhere in wrist, forearm, elbow or may be in shoulder or may be in combination of one or more site. ${ }^{8,11}$

Manipulation maneuver was discussed with parents and a formal consent was taken beforehand. In all cases,supination-flexion technique (Figure 1) being the standard method mentioned in most of the literature was done first. In 45 (91.8\%)patients, reduction was successful on the first attempt. In $2(4.1 \%)$ patients, the same technique had to be repeated once to achieve reduction. Reduction was not achieved even after 2 attempts of supination-flexion maneuver in 2(4.1\%) patients. Hyperpronation method (Figure 2)was then performed in these 2 children after an interval of 15 minutes. One patient was successfully reduced but we failed in one case in the whole study population.

Most commonly used methods for reduction of pulled elbow are supination-flexion manoeuvres and hyperpronation. ${ }^{11,12}$ Though most of the standard literature still recommend supination-flexion technique as a method of reduction,a few recent trials suggested that hyperpronation maneuver was more efficient at the first attempt, easier for physicians and less painful for the children. ${ }^{13-16} \mathrm{~A}$ Cochrane Database Systematic Review ${ }^{17}$ to compare the effectiveness and painfulness of the different methods used to manipulate a pulled elbow in young children concluded that there was limited evidence at that time and recommended that a high-quality randomised trial be performed to strengthen the evidence.

We think both methods are easy to perform. Individual clinicians might choose to select any depending on their experience.

The prognosis of pulled elbow, after reduction, is excellent although recurrence might occur in few, mostly in first 2 years of life. ${ }^{18,19}$ In our series, 3 had recurrence on follow up. Two had affliction of the same hand. In one patient, recurrence involved the opposite hand. All of them, however, were reduced successfully.

Diagnosis of pulled elbow is mostly clinical. Unnecessary imaging has to be avoided. ${ }^{8,19,20}$ An X-ray of the elbow may be needed if the history consists of falling from a high place or tumbling, or if the precise history is unclear and there are abnormal physical examination findings. ${ }^{8,19}$

\section{CONCLUSION}

In conclusion, pulled elbows are usually caused by a sudden pull or jerk to the arm. Most of them generally have a typical history and clinical presentation. Diagnosis is quite easy and most cases can easily be corrected with simple reduction technique without much failure and complication. Every paediatrician therefore must learn to diagnose and treat the condition with confidence as most of such children are brought to pediatricians first. An important part of the management is educating parents about the risk of recurrence and how to avoid them happening.

\section{REFERENCES}

1. Schutzman SA and Teach S. Upper-extremity impairment in young children. Ann Emerg Med 1995;26(4):474-479.

2. Choung $W$ and Heinrich SD. Acute annular ligament interposition into the radiocapitellar joint in children (nursemaid's elbow) $\mathrm{J}$ PediatrOrthop 1995;15(4):454-456.

https://doi.org/10.1097/01241398-199507000-00008

3. Matles $\mathrm{AL}$ and Eliopoulos K. Internal derangement of the elbow in children. IntSurg 1967;48(3):259-263.

4. Kosuwon W, Mahaisavariya B, Saengnipanthkul S, Laupattarakasem W andJirawipoolwon P. Ultrasonography of pulled elbow. J Bone Joint Surg Br 1993;75(3):421-422. https://doi.org/10.1302/0301-620X.75B3.8496211

5. Vitello S, Dvorkin R, Sattler S, Levy D andUng L. Epidemiology of nursemaid's elbow. West J Emerg Med 2014;15(4):554-557. https://doi.org/10.5811/westjem.2014.1.20813 
6. Irie T, Sono T, Hayama $\mathrm{Y}$, Matsumoto $\mathrm{T}$ and Matsushita M. Investigation on 2331 cases of pulled elbow over the last 10 years. Pediatr Rep 2014;6(2):5090. https://doi.org/10.4081/pr.2014.5090

7. Asher MA. Dislocations of the upper extremity in children. OrthopClin North Am 1976;7(3):583-591.

8. Sankar NS. Pulled elbow. J R Soc Med 1999;92(9):462-464. https://doi.org/10.1177/014107689909200907

9. Schunk JE. Radial head subluxation: epidemiology and treatment of 87 episodes. Ann Emerg Med 1990;19:1019-1023.

10. Illingworth CM. Pulled elbow: a study of 100 patients. Br Med J 1998;2:672-674. https://doi.org/10.1136/bmj.2.5972.672

11. Quan $L$ and Marcuse EK. The epidemiology and treatment of radial head subluxation. Am J Dis Child 1985;139:1194-1197. https://doi.org/10.1001/archpedi.1985.02140140028018

12. TahaAM. The treatment of pulled elbow: a prospective randomized study. Arch Orthop Trauma Surg 2000;120(5-6):336-337. https://doi.org/10.1007/s004020050477

13. Garcia-Mata $S$ and Hidalgo-Ovejero A. Efficacy of reduction maneuvers for "pulled elbow" in children: a prospective study of 115 cases. J PediatrOrthop 2014;34(4):432-436. https://doi.org/10.1097/BPO.0000000000000130

14. Gunaydin $\mathrm{YK}$, Katirci $\mathrm{Y}$, Duymaz H, Vural K, Halhalli HC, Akcil M, et al. Comparison of success and pain levels of supination- flexion and hyperpronationmaneuvers in childhood nursemaid's elbow cases. Am J Emerg Med 2013;31(7):1078-1081.

https://doi.org/10.1016/j.ajem.2013.04.006

15. Macias CG, Bothner J andWiebe R. A comparison of supination/ flexion to hyperpronation in the reduction of radial head subluxations. Pediatrics 1998;102(1):e10. https://doi.org/10.1542/peds.102.1.e10

16. Bexkens R, Washburn FJ, Eygendaal D, van den Bekerom MP and Oh LS. Effectiveness of reduction maneuvers in the treatment of nursemaid's elbow: a systematic review and metaanalysis. Am J Emerg Med 2017;35(1):159-163. https://doi.org/10.1016/j.ajem.2016.10.059

17. Krul M, van derWouden JC, Kruithof EJ, van SuijlekomSmit LW andKoes BW. Manipulative interventions for reducing pulled elbow in young children. Cochrane Database Syst Rev 2017;7:CD007759. https://doi.org/10.1002/14651858.CD007759.pub4

18. Teach SJ andSchutzman SA. Prospective study of recurrent radial head subluxation. Arch PediatrAdolesc Med 1996;150(2): 164-166. https://doi.org/10.1001/archpedi.1996.02170270046006

19. MohdMiswan MF, Othman MS, Muhamad Effendi F, Ibrahim MI andRozali KN. Pulled/nursemaid's elbow. Malays Fam Physician 2017;12(1):26-28.

20. Scapinelli $R$ andBorgo A. Pulled elbow in infancy: diagnostic role of imaging. Radiol Med (Torino) 2005;110(5-6):655-664.

\section{Authors Contribution:}

BB- Concept, manuscript writing and critical revision; MD, AR-Compilation of records, review of literature; MK, MM, AS- Manuscript editing.

Work attributed to:

Department of Pediatric Medicine, Burdwan Medical College, Burdwan, West Bengal, India.

Orcid ID:

Dr. Biswajit Biswas - (1) https://orcid.org/0000-0002-9179-3098

Source of Support: None, Conflicts of Interest: None. 